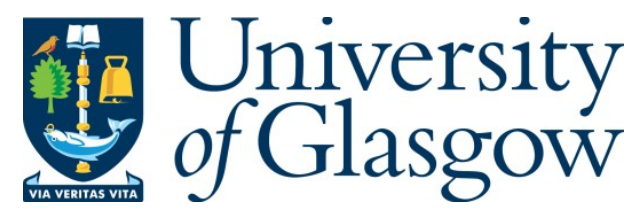

Van Puyvelde, D. (2020) European intelligence agendas and the way

forward. International Journal of Intelligence and CounterIntelligence, 33(3), pp. 506513.

(doi: $\underline{10.1080 / 08850607.2020 .1754666})$

This is the Author Accepted Manuscript.

There may be differences between this version and the published version. You are advised to consult the publisher's version if you wish to cite from it.

https://eprints.gla.ac.uk/214021/

Deposited on: 15 April 2020

Enlighten - Research publications by members of the University of Glasgow http://eprints.gla.ac.uk 


\title{
European intelligence agendas and the way forward
}

\author{
Damien Van Puyvelde \\ University of Glasgow \\ Scottish Centre for War Studies \\ 10 University Gardens \\ G12 8QH Glasgow \\ UNITED KINGDOM \\ Damien.VanPuyvelde@glasgow.ac.uk
}

\section{Biographical note:}

Dr. Damien Van Puyvelde is a Lecturer in Intelligence and International Security at the University of Glasgow, and Research Fellow at the Institute for Strategic Research (IRSEM, French Ministry for Armed Forces). His latest books include Cybersecurity: Politics, Governance and Conflict in Cyberspace (Polity, 2019), Outsourcing US Intelligence: Contractors and Government Accountability (Edinburgh University Press, 2019), and Researching National Security Intelligence: Multidisciplinary Approaches (Georgetown University Press, 2019). 


\section{European intelligence agendas and the way forward}

The landscape of intelligence and security cooperation in Europe can be compared to an impressionist painting. From afar, observers can identify homogenous zones, representing the convergence of national interests and priorities that drives cooperation. Upon closer examination, this landscape reveals a variety of brushstrokes and differences. The oeuvre is complex and prone to multiple interpretations, depending on the position and predispositions of the observer. An examination of converging and diverging trends in the European intelligence landscape suggests that there is not one but multiple European intelligence agendas that partially overlap. This situation is unlikely to change in the next decade, but we can expect intelligence cooperation to deepen.

\section{Drivers of cooperation}

The common political and cultural heritage of European countries is a fundamental driver of their integration. This heritage has facilitated the emergence of similar worldviews and values that are expressed and guaranteed by legal instruments such as the European Convention on Human Rights and the Treaty on European Union. These texts protect the rights of Europeans and the free movement of people, goods and services across the European Union (EU). The maintenance of this area of freedom, security and justice requires coordination between law enforcement and intelligence agencies to mitigate transnational threats such as organized crime and terrorism.

European institutions have produced a series of strategic documents that have sought to define a common vision and priorities. This common vision has taken the form of a common foreign 
and security policy, which requires intelligence capabilities to inform European decisionmakers. According to the latest EU Global Strategy "security, including defense, is an integral part of the European project," and 70\% of Europeans support a strong EU role in the world. ${ }^{1}$ This strategy identifies the security of the Union, state and social resilience "to our east and south", an integrated approach to conflicts and crises as well as cooperative regional orders and global governance for the $21^{\text {st }}$ century as its key priorities. ${ }^{2}$ In practice, civilian and military missions involve EU member states and personnel worldwide. Integration in this area has notably led to 25 member states to develop a Permanent Structured Cooperation (PESCO) on defense since 2017, organizing common military trainings and joint capabilities. This initiative is supported by a Single Intelligence Analysis Capacity (SIAC), which relies on civil-military cooperation to improve situational awareness. Over the long term, European decision makers hope that a "common strategic culture" will facilitate "convergence in threat assessment," and "commitment to common responses."

Common threats are another key driver of European intelligence cooperation. Since the late 1960s, European countries and their partners have sought to develop intelligence and security cooperation to mitigate the terrorist threat. This effort is well documented and has led to informal cooperation through the Club de Berne, the Counter Terrorism Group (CTG) and as multilateral institutions like Europol. ${ }^{4}$ The establishment of a number of platforms for sharing data and information between partner services, most recently via the CTG in The Hague, demonstrates that national services have felt a need for increased cooperation and developed a degree of trust. A recent survey shows European people strongly support such initiatives. ${ }^{5}$ The existence of institutions like Europol with their own bureaucratic interests acts, in turn, as a further vector of integration in the fight against transnational crime and terrorism. 
In the last decade, international pressures have reinforced the need for European intelligence cooperation. The possibility of an American retrenchment raises questions about the alignment of interests and worldviews that have long defined the transatlantic alliance. For some leaders, this situation underlines the need for greater European investment in its own defense and security. ${ }^{6}$ Developing strong European cooperation is particularly important at a time when Russia is challenging the sovereignty of European countries in its traditional zone of influence and beyond. Instability in the parts of North Africa and the Middle East has affected Europe's Southern borders. The rise of cyber threats, and their global nature, further challenges European countries. $^{7}$ These trends will continue to shape and challenge European security throughout the 2020s, compelling European countries to work together.

One of the latest additions to the European security landscape is the Intelligence College in Europe (ICE), which aims to foster the emergence of a common European intelligence culture. The College proposes to organize periodic workshops as well as a common learning experience across different European cities to bring intelligence officers together. The aim is not to provide a new channel for operational cooperation - these channels already exist elsewhere - but to grease the wheels of European intelligence cooperation, to socialize intelligence officers so that they can share their experiences and develop a better understanding of each other's situation. Constructivist scholarship suggests that this kind of socialization can foster the emergence of shared norms of behavior and, in turn, a common culture. ${ }^{8}$ In the best-case scenario, ICE will foster long-term trust between European intelligence professionals, a key ingredient to successful cooperation. ${ }^{9}$

In the next decade, the drive toward European intelligence cooperation, could lead to the adoption of a common European intelligence strategy, highlighting the liberal democratic 
values and security priorities that European countries already share. At a more practical level, this common vision and the socialization of practitioners could support the development of strategic analysis following the European Intervention Initiative (EII/EI2) and its emphasis on sharing strategic foresight and scenario development. ${ }^{10}$ European countries could similarly pool some of their expertise to develop a shared vision of possible futures in the form of a Global Trends report. ${ }^{11}$ The development a European predictive market for geopolitical forecasting is another possibility. Such initiatives would leverage the diversity of European experiences and views, within and beyond national intelligence services, to generate comprehensive strategic analysis.

A number of observers argue that the growth of international intelligence cooperation in the last decade has rendered traditional forms of accountability, rooted in the sovereign nation state, insufficient. ${ }^{12}$ The European Parliament has produced a handful of detailed investigations into transnational intelligence practices and can be expected to reiterate its efforts when new revelations will inevitably emerge in the media. ${ }^{13}$ In a common statement, the oversight boards of Belgium, Denmark, the Netherlands, Norway and Switzerland, have recently proposed to strengthen the oversight of international data exchange between their respective intelligence and security services. ${ }^{14}$ To develop international oversight, the five organizations propose to "minimize secrecy" between them so that they can discuss the intelligence that is exchanged between their services. The overseers want to "develop new legal and technical methods of oversight, in order to effectively assess the system of international data exchange and the existence and functioning of common safeguards for the protection of fundamental rights." 15 Periodic meetings between their chairs and staff will also support the exchange of best oversight practices. ${ }^{16}$ This initiative is likely to gather some momentum given increased public demand for intelligence oversight following the "global surveillance disclosures." A promising 
idea would be for European oversight bodies, national intelligence services, and civil society actors to jointly develop a European code of intelligence ethics, emphasizing European countries' attachment to liberal democratic values.

While drivers of cooperation have and will continue to foster a common vision for European security and a degree of intelligence cooperation, the development of a common European intelligence structure is not realistic absent further political integration. ${ }^{17}$ In the best-case scenario, trends and events will converge to make intelligence cooperation more comprehensive and effective, helping the services to better anticipate and mitigate the broad array of threats they confront.

\section{The primacy of national interests}

The prominence of sovereign nation states significantly limits European intelligence integration. Despite the effort to develop multilateral European cooperation, intelligence remains driven by a realist logic that prioritizes national interests and security. While European organizations like Europol and the EU Intelligence and Situation Centre (INTCEN) collate and analyze intelligence, they do not gather sensitive information from protected sources. Neither do they control the intelligence process in the same way national intelligence agencies do. In the absence of further integration at the political level (a federal European Union), a selfsufficient European intelligence system will not emerge.

The primacy of national interests in security affairs is firmly established in Western political systems, and this situation is unlikely to change in the long term. The Treaty on European Union is clear: "national security remains the sole responsibility of each Member State." 18 This 
is also clearly the case for these European countries that are not part of the EU. National intelligence agencies continue to maintain a privileged access to protected sources and methods, and have no interest in ceding their control to European institutions or any other supra-national body. Unsurprisingly, intelligence professionals working for European countries similarly recognise the primacy of national interests. ${ }^{19}$

The extent to which national interests overlap determines the European intelligence agenda. While all European countries agree on the threats posed by terrorism, cyber-attacks and criminality to name a few examples, they prioritize and address these threats in different manners based on their national circumstances. This situation, which is encountered across a number of policy areas in Europe, creates a variable geometry in which groups of states cooperate more on some issues than others do. European integration needs to provide sufficient flexibility for states to converge or diverge depending on the issue. From this perspective, it is more accurate to talk about European intelligence agendas in the plural.

Despite common ideals and threats, the interests and priorities of European countries diverge to a certain extent and will continue to do so. Long-term factors such as geography (e.g. proximity to Russia, the existence of maritime borders etc.), historical legacies (e.g. postcommunist transition, colonial heritage etc.), political cultures, resources and levels of investment in national security vary significantly from one European country to another, and determine different ends, ways and means. Political requirements for foreign, domestic and military intelligence vary accordingly. Not all the European countries desire to project power on the international scene in the same way France and the United Kingdom do. The Baltic and Nordic countries have a greater interest in sharing warning intelligence on their Russian neighbor than Luxemburg or Italy. In the short term, elected officials' priorities and their level 
of attachment to European ideals vary and this situation creates divergences, which can complicate the politics of European cooperation.

National differences have affected the development of intelligence services, fostering a variety of ways to talk about, understand and organize intelligence as a function of government. ${ }^{20}$ These differences limit the utility and the possibility of European intelligence integration. Researchers have noted that a fully integrated European intelligence capability might not be efficient, and therefore desirable. ${ }^{21}$ The variety of European approaches and national interests would pose a number of coordination challenges to a centralized European intelligence agency. The coexistence of a variety of national services offers a diversity of perspectives and experiences, which justifies the need for cooperation.

The vast majority of the academic literature on European intelligence cooperation focuses on counter-terrorism, an area in which national interests strongly converge and intelligence services have a very strong incentive to cooperate. In a number of other domains - from diplomacy to politics to economics - national priorities are not aligned as strongly. These differences create an incentive for European countries to collect intelligence and analyse each other's positions to better understand and influence their partners. Some services might feel uncomfortable at the idea of sharing sensitive information with partners that do not perceive and assess threats in the same way, for example because their regime and services have historically been closer to Russia. Public expectations of the roles of intelligence services might, similarly differ from one European country to the other. ${ }^{22}$ In the absence of further research, these areas of divergence remain poorly understood by external observers. 
To conclude, the emergence of a supra-national European intelligence system is not realistic. Without a significant (and at the moment highly unlikely) transfer of political power from member states to the EU, European institutions will not centralize intelligence more effectively than European countries cooperate. The prominence of informal cooperation channels suggests that Brexit and any other possible future exit of the EU will have a minimal impact on European intelligence cooperation. ${ }^{23}$ This cooperation has been expanding for the last decades and is likely to deepen. The development of common platforms to share data, information, best practices, and socialize intelligence professionals is likely to facilitate the emergence of common practices and products at the European level.

The European intelligence agenda(s) cannot and should not be defined by the services alone. The threats challenging Europe have a societal dimension and are best understood and tackled with the help of broader society. At a time when secrecy has become increasingly difficult to maintain, ${ }^{24}$ a degree of openness and engagement with civil society has become necessary for intelligence services to inform the public and overcome common concern and misrepresentations about national security intelligence at the national and European levels. Public expectations need to be understood, managed and integrated for European intelligence cooperation to be successful.

\section{References}

${ }^{1}$ The European Union's Global Strategy. Three Years On, Looking Forward, pp.10-12.

${ }^{2}$ Ibid, p. 10.

${ }^{3}$ Ibid, p. 12.

${ }^{4}$ See for example Aviva Guttmann, "Combatting Terror in Europe: Euro-Israeli

Counterterrorism Intelligence Cooperation in the Club de Berne (1971-1972)," Intelligence and National Security, Vol. 33, No. 2 (2018), pp. 158-75.

${ }^{5}$ European Commission, Special Eurobarometer 464b, Summary, "European's Attitudes towards Security," December 2017, pp. 5-6.

${ }^{6}$ Présidence de la République, Initiative pour l'Europe, Paris, 26 September 2017. 
${ }^{7}$ See for example recent events organised by the European Union Agency for Cybersecurity, "2020 CTI-EU. Bonding EU cyber Threat Intelligence", available at

https://www.enisa.europa.eu/events/2019-cti-eu/2019-cti-eu-bonding-eu-cyber-threatintelligence

${ }^{8}$ Jeffrey T. Checkel, "International Institutions and Socialization in Europe: Introduction and Framework," International Organization, Vol.59, No.4 (2005), pp. 801-26.

${ }^{9}$ Stéphane Lefebvre, "The Difficulties and Dilemmas of International Intelligence

Cooperation," International Journal of Intelligence and CounterIntelligence, Vol. 16, No. 4 (2003), p. 528.

${ }^{10}$ Dick Zandee and Kimberley Kruijver, "The European Intervention Initiative. Developing a shared strategic culture for European defence," Clingendael - Netherlands Institute of International Relations, September 2019, p. 4.

${ }^{11}$ National Intelligence Council, Global Trends: Paradox of Progress, January 2017;

Ministry of Defence, Global Strategic Trends. The Future Starts Today, 2018.

${ }^{12}$ Richard Aldrich, 'Global Intelligence Co-operation versus Accountability: New Facets to an Old Problem', Intelligence and National Security, Vol. 24, No.1 (2009), p. 35; Monica Den Boer, "Counter-Terrorism, Security and Intelligence in the EU: Governance Challenges for Collection, Exchange and Analysis," Intelligence and National Security Vol.30, No.2-3 (2015), pp. 410-18; About intel, "Mission," available at https://aboutintel.eu/mission/ ${ }^{13}$ European Parliament, Report on the existence of a global system for the interception of private and commercial communications (ECHELON interception system), 11 July 2001; idem, Report on the alleged use of European countries by the CIA for the transportation and illegal detention of prisoners, 30 January 2007.

${ }^{14}$ Belgian standing intelligence agencies review committee, Danish intelligence oversight board, Review committee on the intelligence and security services - The Netherlands, The Norwegian Parliamentary Intelligence Oversight Committee, Independent Oversight Authority for Intelligence Activities, "Strengthening the oversight of international data exchange between their respective intelligence and security services," 22 October 2018, available at https://comiteri.be/images/pdf/publicaties/Common_Statement_EN.pdf.

${ }^{15}$ Ibid.

${ }^{16}$ Charter of the Intelligence Oversight Working Group, 12 December 2019, available at https://comiteri.be/images/pdf/Charter_Intelligence_Oversight_Working_Group_signed_12_ December_2019.pdf

${ }^{17}$ For an argument in favour of an EU Intelligence Service see John M. Nomikos, "A European Union Intelligence Service for Confronting Terrorism," International Journal of Intelligence and CounterIntelligence, Vol.18, No.2 (2005): 191-203.

${ }^{18}$ Treaty on European Union, Article 4(2).

${ }^{19}$ Private conversations with multiple professionals, 2019.

${ }^{20}$ Bob de Graaf and James M. Nyce, Handbook of European Intelligence Cultures (Lanham: Rowman \& Littlefield, 2016), xxx.

${ }^{21}$ Björn Müller-Wille, "The Effect of International Terrorism on EU Intelligence Cooperation," Journal of Common Market Studies Vol. 48, No.1 (2008), p. 49.

${ }^{22}$ For a British survey see Graeme Davies and Robert Johns, 'British Public Confidence in MI6 and Government Use of Intelligence: The Effect on Support for Preventive Military Action', Intelligence and National Security, Vol. 27, No. 5 (2012), pp. 669-88.

${ }^{23}$ Damien Van Puyvelde, "Profiles in Intelligence: An Interview with Sir David Omand," Intelligence and National Security, Vol. 35, No. 2 (2020), p. 177.

${ }^{24}$ Richard Aldrich and Christopher Moran, "'Delayed Disclosure': National Security, Whistle-Blowers and the Nature of Secrecy," Political Studies, Vol. 67, No.2 (2019), pp. 291-306. 